\title{
Development of tools to rapidly identify cryptic species and characterize their genetic diversity in different European kelp species
}

\author{
Stéphane Mauger ${ }^{1}$ (D) Louise Fouqueau $^{1} \cdot$ Komlan Avia $^{2}$ (D) $\cdot$ Lauric Reynes $^{3}$ (D) $\cdot$ Ester A. Serrao $^{4}$ (D) . João Neiva ${ }^{4}$ (D) . \\ Myriam Valero ${ }^{1}$ (i)
}

Received: 22 June 2021 / Revised: 20 September 2021 / Accepted: 20 September 2021

(c) The Author(s), under exclusive licence to Springer Nature B.V. 2021

\begin{abstract}
Marine ecosystems formed by kelp forests are severely threatened by global change and local coastline disturbances in many regions. In order to take appropriate conservation, mitigation, and restoration actions, it is crucial to identify the most diverse populations which could serve as a "reservoir" of genetic diversity. This requires the development of specific tools, such as microsatellite markers to investigate the level and spatial distribution of genetic diversity. Here, we tested new polymorphic microsatellite loci from the genome of the kelp, Laminaria digitata, and tested them for cross-amplification and polymorphism in four closely related congeneric species (Laminaria hyperborea, Laminaria ochroleuca, Laminaria rodriguezii, and Laminaria pallida). Adding these 20 new microsatellite loci to the ten $L$. digitata loci previously developed by Billot et al. (Mol Ecol 7:1778-1780, 1998) and Brenan et al. (J R Soc Interface 11:1-12, 2014) and to the ten L. ochroleuca loci previously developed by Coelho et al. (Conserv Genet Resource 6:949-950, 2014), we retained a total of 30 polymorphic loci for L. digitata, 21 for L. hyperborea, 16 for L ochroleuca, 18 for L. rodriguezii, and 12 for $L$. pallida. These markers have been tested for the first time in the last two species. As predicted, the proportion of markers that cross-amplified between species decreased with increasing genetic distance. In addition, as problems of species identification were reported in this family, mainly between $L$. digitata and Hedophyllum nigripes, but also between L. digitata, L. hyperborea, and L. ochroleuca in areas where their range distributions overlap, we report a rapid PCR identification method based on species-specific COI mitochondrial primers that allows these four species of kelp to be rapidly distinguished.
\end{abstract}

Keywords Genetic diversity $\cdot$ Microsatellite markers $\cdot$ Cross-amplification $\cdot$ Species identification $\cdot$ Brown seaweed

Stéphane Mauger and Louise Fouqueau contributed equally to the paper.

Stéphane Mauger

stephane.mauger@sb-roscoff.fr

$\triangle$ Myriam Valero

myriam.valero@sb-roscof.fr

1 IRL EBEA 3614, Evolutionary Biology and Ecology of Algae, CNRS, Sorbonne Université, UC, UACH, Station Biologique de Roscoff, CS 90074, Place Georges Teissier, 29688 Roscoff cedex, France

2 Université de Strasbourg, INRAE, SVQV, UMR-A 1131, 68000 Colmar, France

3 Aix Marseille Univ, Université de Toulon, CNRS, IRD, MIO, Marseille, France

4 Centro de Ciências Do Mar (CCMAR), Universidade Do Algarve, Faro, Portugal

\section{Introduction}

Kelp forests are mainly formed by large brown algae of the order Laminariales, are present along rocky shores of temperate to polar regions and occupy approximately $36 \%$ of the world's coastlines (Jayathilake and Costello 2021). They build major biogenic habitats that are one of the most diverse and productive ecosystems (Steneck et al. 2002; Bolton 2010; Krumhansl et al. 2016; Teagle et al. 2017) but are increasingly prone to decline due to climate change (e.g., Wernberg et al. 2012; Smale 2020) and anthropogenic pressures, including sedimentation and turbidity, as well as direct exploitation, such as for alginate (Teagle et al. 2017). A wealth of studies has revealed that kelp populations can be extremely structured in space and that genetic diversity is not evenly distributed across the species ranges. Instead, populations can be considerably differentiated and genetic diversity 
concentrated in refugial areas of disproportionate conservation value, e.g., where species were able to persist across past glacial cycles (Assis et al. 2018; Neiva et al. 2020). In the context of the management of genetic resources, it is crucial to identify the most diverse populations which could serve as a "reservoir" of genetic diversity in order to inform appropriate conservation and restoration actions (Valero et al. 2011; Wernberg et al. 2018).

Within the order Laminariales, species of the Laminaria genus occur mainly in the northern Hemisphere on both Atlantic and Pacific coasts (Bartsch et al. 2008). The recent phylogeny of Rothman et al. (2017) grouped the six Atlantic and the Mediterranean species of this genus within the same clade. Some of these species are distributed in the northern Hemisphere with three of them (L. digitata (Hudson) J.V.Lamouroux, L. hyperborea (Gunnerus) Foslie, and L. ochroleuca Bachelot Pylaie) being partially sympatric along the NE Atlantic coast (Bartsch et al. 2008; Araújo et al. 2016), while the other one (L. rodriguezii Bornet) is a deep-water Mediterranean-endemic (Ballesteros 2006; Araújo et al. 2016). L. ochroleuca has also been observed in deep waters in some parts of its distribution (Araújo et al. 2016; Assis et al. 2018). The other part of the clade is constituted by two species occurring in Southern Atlantic, along a restricted part of the Brazilian coast (the deep-water L. abyssalis AB Joly \& EC Oliveira; Marins et al. 2014) and the Namibian and South African coasts (L. pallida Greville; Rothman et al. 2017). Molecular tools can be useful to estimate the conservation status of a species (Soulé and Mills 1992; Allendorf and Ryman 2002), in addition to the demographic history and the evolutionary and conservation value of distinct populations. In the genus Laminaria, ten microsatellite markers have been specifically developed for L. digitata (Billot et al. 1998; Brennan et al. 2014) and an additional ten for L. ochroleuca (Coelho et al. 2014). These genetic markers cross-amplified across these two species as well as for L. hyperborea and were used for phylogeography and connectivity studies (Billot et al. 2003; Valero et al. 2011; Couceiro et al. 2013; Robuchon et al. 2014; Assis et al. 2018; Evankow et al. 2019; King et al. 2019; Liesner et al. 2020; Neiva et al. 2020; Schoenrock et al. 2020), but no microsatellite markers have been developed for the other species of the same genus.

Another challenge in Laminaria genus that can be overcome by the use of molecular tools is field misidentification of cryptic species (species that are problematic to identify based on morphological criteria), which can lead to inaccurate estimation of population connectivity and dynamics and therefore can have deleterious consequences on their conservation (Saunders 2005; Longtin and Saunders 2015). Taxonomic confusions based on morphological traits were reported between species of this family with overlapping range distributions (e.g., between $L$. digitata and $L$. hyperborea, Schoenrock K. M., Krueger-Hadfield S. A., Robuchon M., pers. comm.), especially between $L$. digitata and Hedophyllum nigripes (J.Agardh) Starko, S.C.Lindstrom \& Martone 2019 (as Saccharina groenlandica, Longtin and Saunders 2015; as Saccharina nigripes, Longtin and Saunders 2016; as Hedophyllum nigripes, Neiva et al. 2020). These problems are also frequent when dealing with juvenile stages. In these situations, DNA-based methods, such as DNA barcoding of the mitochondrial cytochrome $\mathrm{c}$ oxidase subunit I gene (COI hereafter), have been proven especially useful to uncover and/or confirm the identity of cryptic species where classical taxonomy were reported problematic (McDevit and Saunders 2009). Indeed, molecular barcoding was reported to be the only way to distinguish $L$. digitata from H. nigripes in the European Arctic where both species share the same habitat (Fredriksen et al. 2019). However, a faster and cheaper method is still needed, particularly when the ID of a large number of samples needs to be quickly confirmed, such as when selecting individuals for physiological experiments.

In this study, we developed new microsatellite markers based on the genome of L. digitata and tested them for transferability (cross-amplification and polymorphism) in four other Laminaria species (L. hyperborea, L. ochroleuca, L. rodriguezii, and $L$. pallida). In parallel, we developed a cheap and rapid PCR species identification method based on species-specific primers for the COI gene to avoid misidentification between sister species and with $H$. nigripes, a species which is frequently mistaken for Laminaria species.

\section{Materials and methods}

\section{Sample collection and DNA extraction}

Two types of sampling were used in this paper: (1) "wide scale sampling" for which we used one to several individuals sampled from different populations over the entire range distribution of the different species; (2) "single population sampling" for which we used individuals coming from a unique population. The wide scale sampling was designed to capture the extent of variability over the entire range of the species, in order to characterize new microsatellite markers in L. digitata and study their transferability in four sister species. When possible, a minimum of ten localities per species was retained, from which a single individual per locality was used (giving a total of 11 to 15 individuals for $L$. digitata, $L$. hyperborea, and L. ochroleuca). We had access to only four localities for $L$. rodriguezii; therefore, two individuals were analyzed from each locality (giving a total of eight individuals). For L. pallida as we had only access to samples from a single locality, 11 individuals were used, giving a total of 58 individuals across the species (Supp. Table 1). The single 
population sampling was used to assess the polymorphism within a population with a minimum of 11 to 32 individuals for each species (giving a total of 107 individuals, Supp. Table 1).

The molecular tool developed to identify species (called "species identification molecular tool" hereafter) is based on mtDNA and has been developed from the wide scale sampling dataset for L. digitata, L. hyperborea, and $L$. ochroleuca to which we have added $H$. nigripes (eight individuals from four localities, Supp. Table 1), a species that is morphologically difficult to distinguish from $L$ digitata.

For all samples, genomic DNA was extracted from 5 to $10 \mathrm{mg}$ of dry tissue using the Nucleospin 96 plant kit (Macherey-Nagel, Germany). The extraction was performed according to the manufacturer's instructions except that samples were left in the PL1 lysis buffer at $65^{\circ} \mathrm{C}$ for $15 \mathrm{~min}$ rather than $30 \mathrm{~min}$. The extracted DNA was eluted in 200 $\mu \mathrm{L}$ of the supplied elution buffer.

\section{Microsatellite loci screening and primer design}

A total of $81,223 \mathrm{~L}$. digitata unique contigs obtained from the draft assembled genome of a male gametophyte (LamiDigitata_Contigs_V1.fa) of the Phaeoexplorer project (unpublished, M. Cock pers. comm.) were screened to identify and remove contigs containing microsatellite markers that had been previously published (Supp. Table 2). These represented a total of 23 contigs associated with previously developed microsatellite loci for $L$. digitata (Billot et al. 1998; Brennan et al. 2014) and L. ochroleuca (Coelho et al. 2014). A total of 81,200 unique contigs were screened for di-, tri-, tetra-, and pentanucleotide microsatellite motifs using the SPUTNIK program (http:// abajian.net/sputnik/), which uses a recursive algorithm to identify repeated patterns of nucleotides with a length ranging between two and five. PCR amplification primers were designed using Primer3 (Rozen and Skaletsky 2000) for regions with a flanking sequence of sufficient length on either side of the repeated motif. In-house scripts were used to specify the primer selection conditions, which used default values for all parameters except the optimum melting temperature, which was set to $60{ }^{\circ} \mathrm{C}$ (range $57-62{ }^{\circ} \mathrm{C}$ ), and the expected product size which was set at $400 \mathrm{bp}$.

In order to cost-effectively test these primers for amplification, we reduced the number of selected microsatellite regions to 96 (the capacity of a microtiter plate), by employing the following criteria: we first eliminated duplicate regions and all regions containing an unknown base $(\mathrm{N})$ within the repeated motifs $(56,034$ microsatellites regions remaining); then, the number of microsatellite regions was further reduced to 96 by selecting the ones with the highest number of repeats for each of the four motif categories (see Supp. Table 3 for details).

\section{Amplification trials of microsatellite loci}

The 96 primer pairs were tested for amplification using DNA from 15 L. digitata individuals (Supp. Table 1). Amplifications were carried out in $10 \mu \mathrm{L}$ reaction volume with $2 \mu \mathrm{L}$ of DNA template diluted to 1:100 and following the instructions from Guzinski et al. (2016). The PCR products labeled with the four different colors were pooled ( 24 pools in total) and diluted 1:10 with water. Next, $2 \mu \mathrm{L}$ of the diluted PCR product pool was added to $10 \mu \mathrm{L}$ of loading buffer made up of $0.5 \mu \mathrm{L}$ of the SM594 size standard (Mauger et al. 2012) and $9.5 \mu \mathrm{L}$ of $\mathrm{Hi}-\mathrm{Di}$ formamide, denatured at $95{ }^{\circ} \mathrm{C}$ for $3 \mathrm{~min}$, and run in an ABI $3130 \mathrm{XL}$ capillary sequencer (Applied Biosystems, USA). Genotypes were scored manually in Genemapper version 4.0 (Applied Biosystems). No product was amplified from 59 of the initial 96 primer pairs for any of the 15 individuals despite several amplification attempts (Supp. Table 3). In addition, 17 other primer pairs were monomorphic, and therefore, further analyses were conducted on the remaining 20 polymorphic markers (Supp. Tables 3 and 4).

\section{Transferability of microsatellite loci and investigation of the levels of polymorphism}

Samples from the wide scale sampling dataset $15 \mathrm{~L}$. digitata; 13 L. hyperborea; 11 L. ochroleuca; 8 L. rodriguezii; and 11 L. pallida, Supp. Table 1) were genotyped for the 20 retained polymorphic primers to assess polymorphism and cross-amplification. Each of the 20 loci was amplified with labeled primers in the same manner as described for the amplification trials, except the addition of $0.3 \mu \mathrm{M}$ of forward fluorescently labeled primer (Eurofins Genomic, Germany) and $0.3 \mu \mathrm{M}$ of reverse primer (see Table 1 for primer information). Amplifications were carried out in the following conditions: initial denaturation at $95^{\circ} \mathrm{C}$ for $5 \mathrm{~min}$, 10 cycles of denaturation at $95{ }^{\circ} \mathrm{C}$ for $30 \mathrm{~s}$, annealing at $68{ }^{\circ} \mathrm{C}$ for $30 \mathrm{~s}\left(-1{ }^{\circ} \mathrm{C}\right.$ per cycle-touchdown to $\left.58^{\circ} \mathrm{C}\right)$, extension at $72{ }^{\circ} \mathrm{C}$ for $30 \mathrm{~s}, 30$ cycles of denaturation at $95{ }^{\circ} \mathrm{C}$ for $30 \mathrm{~s}$, annealing at $58^{\circ} \mathrm{C}$ for $30 \mathrm{~s}$, extension at $72{ }^{\circ} \mathrm{C}$ for $30 \mathrm{~s}$, followed by a final extension of $72{ }^{\circ} \mathrm{C}$ for $10 \mathrm{~min}$. Genotyping were carried out in the same manner as described for the amplification trials.

In addition to these 20 newly developed polymorphic microsatellite loci, we also screened all samples for the microsatellites previously developed for $L$. digitata from a nuclear library (Ld1_124, Ld2_148, Ld2_158, Ld2_167, Ld2_371, Ld2_531, Ld2_704, Billot et al. 1998), from an Expressed Sequence Tag (EST) library (AW401303, CN466672, CN467658, Brennan et al. 2014) and the ones developed for L. ochroleuca from a nuclear library (Lo424, LoIVVIV-10, LoIVVIV-13, LoIVVIV-15, LoIVVIV-16, LoIVVIV-17, LoIVVIV-23, LoIVVIV-24, LoIVVIV-27, 


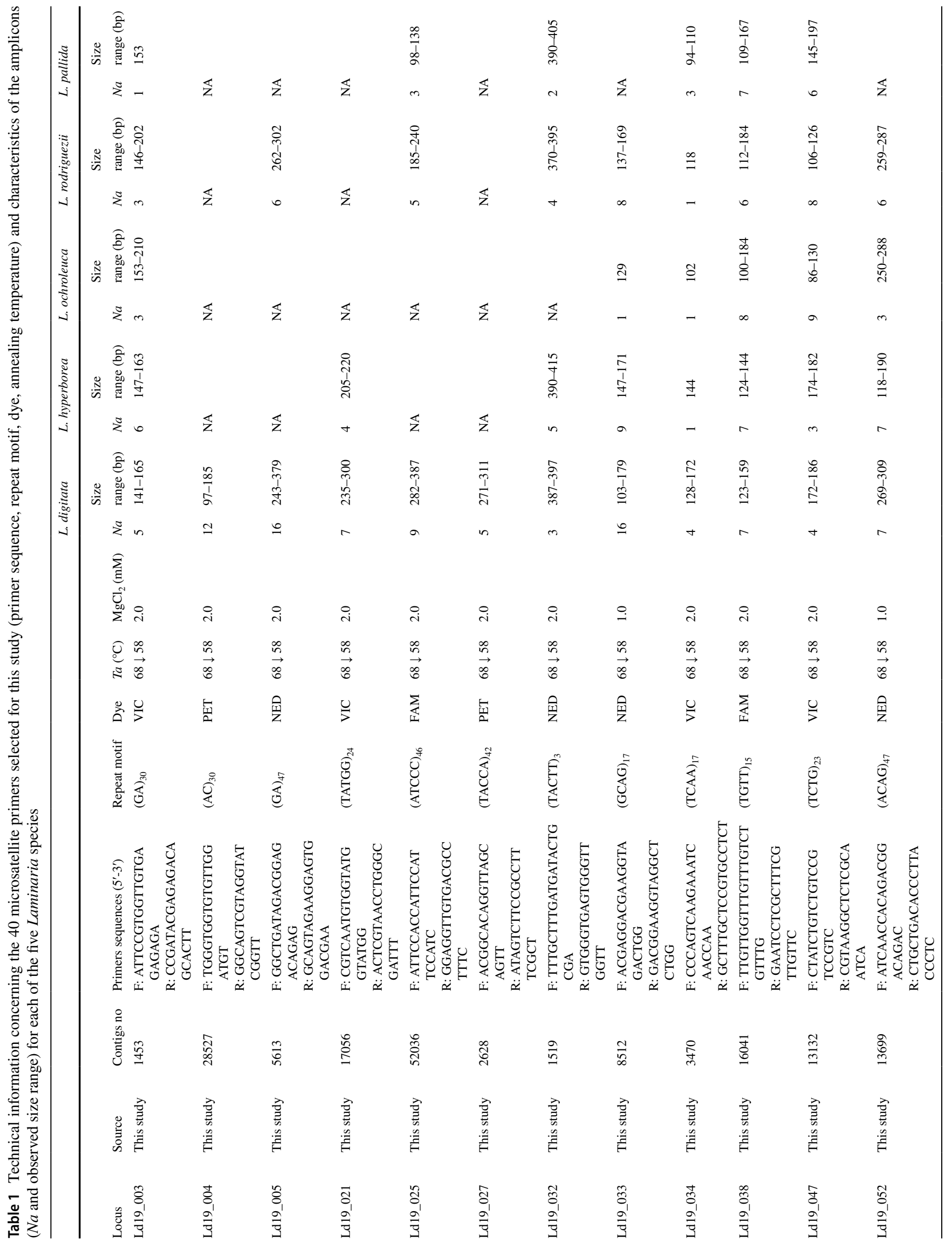




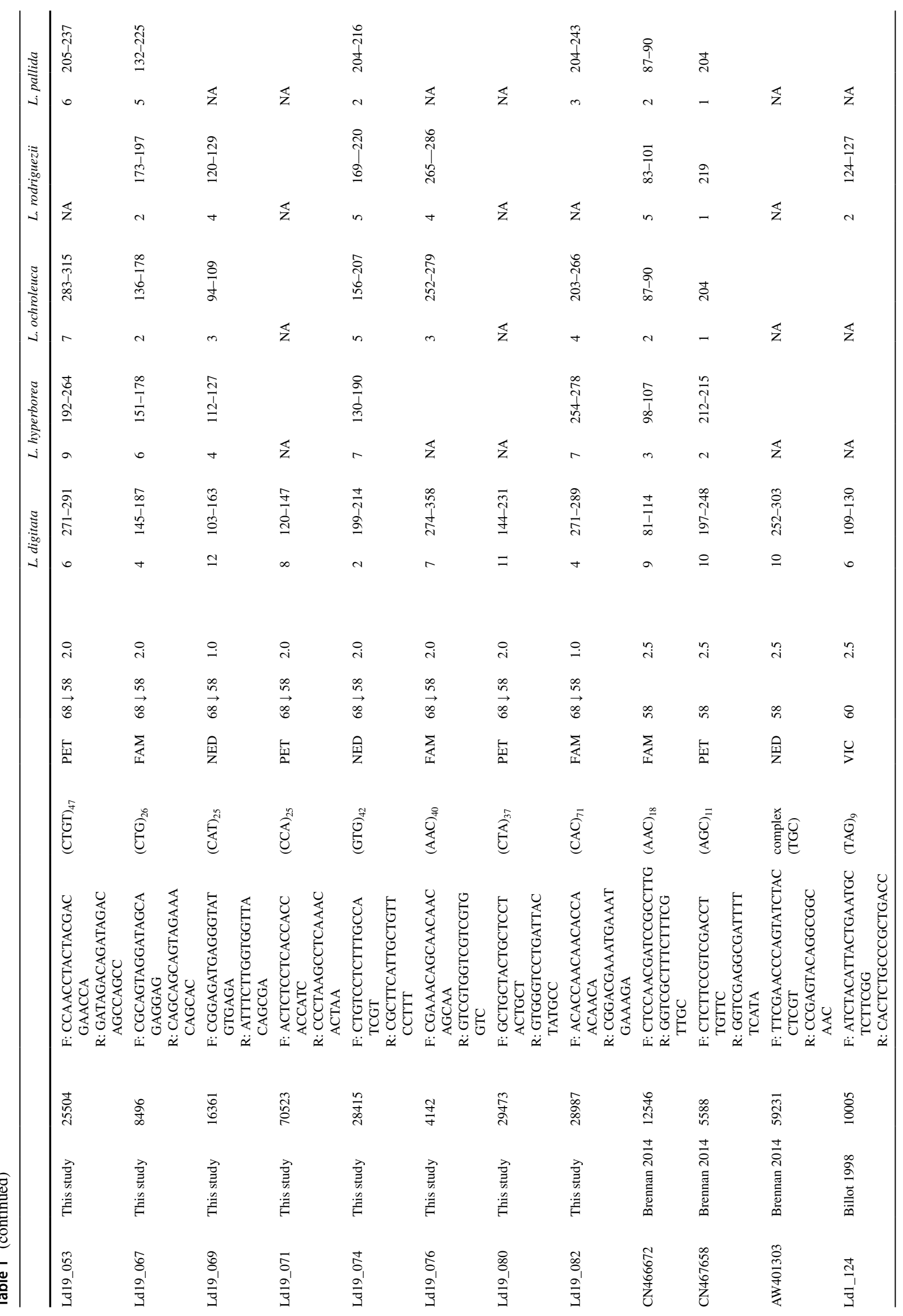




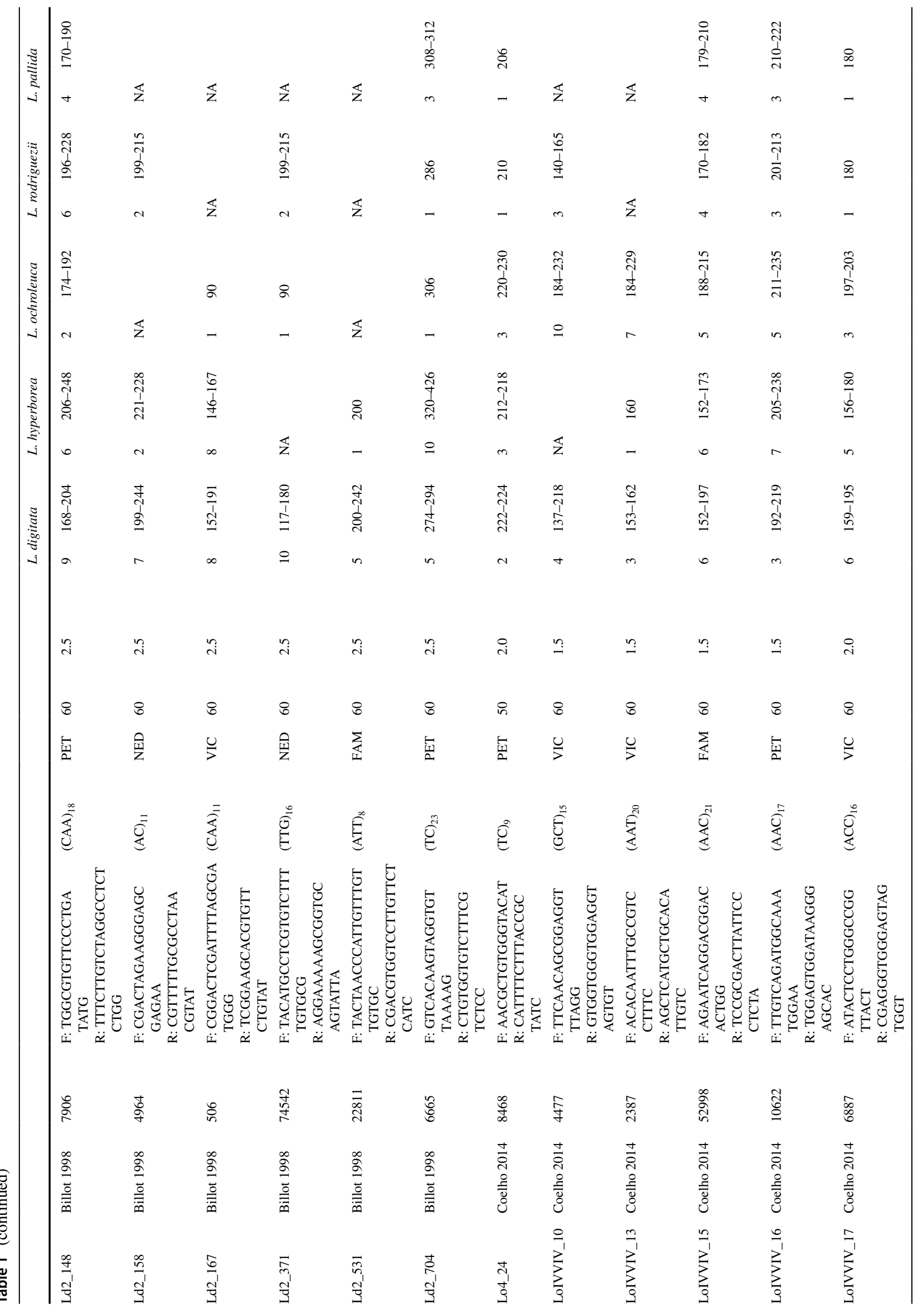




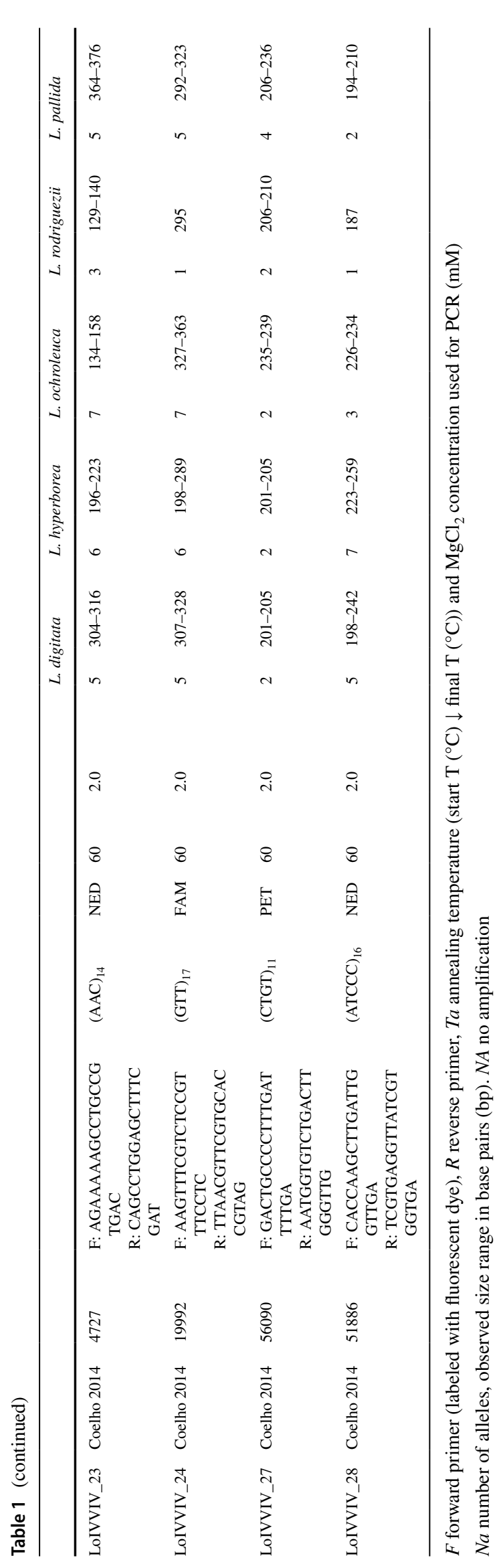


LoIVVIV-28, Coelho et al. 2014), giving a total of 40 microsatellite markers. Exceptionally, a new reverse primer Ld1_124_R2 (5'-CACTCTGCCCGCTGACC$3^{\prime}$ ) was designed for the locus Ld1_124 (using the contig $\left.\mathrm{n}^{\circ} 10,005\right)$ to increase the size of the amplification products (+ $185 \mathrm{bp}$ ) compared to the ones obtained with the primer pairs described in Billot et al. (1998). The purpose of this increase was to facilitate scoring in GENEMAPPER v4.0 (Applied Biosystems). Genotyping was conducted using the same protocol as described in the section "Amplification trials of microsatellite loci."

\section{Genetic analyses}

In order to compare the levels of polymorphism between the set of markers, the 40 markers were amplified in each species using the single population sampling dataset (11 to 32 individuals per populations, Supp. Table 1). Prior to the genetic analysis, we tested for null alleles using MICRO-CHECKER (Van Oosterhout et al. 2004). GENEPOP v4.7.5 (Rousset 2008) was used to test for linkage disequilibrium (global test employing Fisher's method, the following Markov chain parameters were used: 100,000 for dememorization, 1000 batches and 50,000 iterations per batch). The same software was used to obtain the number of observed alleles per locus $(\mathrm{Na})$, observed heterozygosity $(\mathrm{Ho})$, expected heterozygosity $(\mathrm{He})$, the within-population deviation from Hardy-Weinberg equilibrium $\left(F_{I S}\right)$, and its significance. The polymorphic information content $(P I C)$ was calculated with CERVUS (Marshall et al. 1998).

\section{Development of a rapid species identification molecular tool}

A fragment of the mitochondrial COI gene (COI-5P) was obtained for L. digitata, L. hyperborea, L. ochroleuca, and H. nigripes using the primers GAZ_F2 and GAZ_R2 (Lane et al. 2007). Ninety-nine individuals (53 L. digitata, $13 \mathrm{~L}$. hyperborea, 11 L. ochroleuca, and 22 H. nigripes, Supp. Table 1) were sequenced, and four consensus sequences (one per species) were generated using CODONCODEALIGNER (https://www.codoncode.com/). New species-specific primers were designed to amplify shorter fragments using the AMPLIFX program (https://inp.univ-amu.fr/en/ampli fx-manage-test-and-design-your-primers-for-pcr/). These primers were Ld_F2 and Ld_R for L. digitata, Lh_F2 and
Lh_R for L. hyperborea, Hn_R for $H$. nigripes, and PC_F for positive control of PCR (Table 2 and Fig. 1).

In order to test whether the primers could be used to distinguish the four species, two multiplex PCRs containing four primers each were generated PCR1 and PCR2 (Table 2), and the expected sizes for each species were obtained using AMPLIFX. PCR were carried out in $10 \mu \mathrm{L}$ reaction volumes containing $2 \mu \mathrm{L}$ of DNA template diluted 1:100, 1X Green GoTaq Flexi Buffer (Promega, USA), $0.5 \mu \mathrm{M}$ of each primer (Table 2), $2 \mathrm{mM} \mathrm{MgCl}$, $150 \mu \mathrm{M}$ dNTPs (Thermo Fisher Scientific Inc., USA), and 0.35 U GoTaq Flexi Polymerase (Promega). DNA amplifications were carried out in a BioRad DNA Engine Peltier Thermal Cycler under the following conditions: initial denaturation phase at $95{ }^{\circ} \mathrm{C}$ for $5 \mathrm{~min}$, followed by 30 cycles of denaturation at $95^{\circ} \mathrm{C}$ for $30 \mathrm{~s}$, annealing at $50{ }^{\circ} \mathrm{C}$ for $1 \mathrm{~min}$, extension at $72{ }^{\circ} \mathrm{C}$ for $1 \mathrm{~min}$, and a final extension at $72^{\circ} \mathrm{C}$ for $10 \mathrm{~min}$. For each sample, the two multiplex PCRs were pooled, and amplified fragments were visualized under UV light after electrophoresis on $3 \%(\mathrm{p} / \mathrm{w})$ agarose gels stained with ethidium bromide (Fig. 2).

\section{Results}

\section{Development of microsatellites}

In the genome of L. digitata, 305,646 microsatellite motifs were found among the 81,200 unique contigs. The microsatellites contained 33,861 (11.1\%) di-, 151,588 (49.6\%) tri-, $54,408(17.8 \%)$ tetra-, and 65,798 (21.5\%) pentanucleotide motifs (Supp. Table 3). After choosing regions with flanking sequences of sufficient length and giving a product size of $400 \mathrm{bp}$, we obtained 273,231 primer pairs corresponding to $30,900(11.3 \%)$ di-, 138,604 (50.7\%) tri-, 49,062 (18\%) tetra-, and 52,665 (20\%) pentanucleotide repeated motifs (Primer3 output, Supp. Table 3). Among the 96 primer pairs tested, 37 were amplified (including 4 di-, 13 tri-, 12 tetra-, and 8 pentanucleotide repeats, Supp. Table 3) and were retained for further analyses. Twenty out of these 37 putative loci (including 7 tri-, 6 tetra-, 4 penta-, and 3 dinucleotide repeats, Supp. Table 3) produced PCR products of the expected size and were polymorphic. Therefore, the rate of success for each of the four motif categories in the acquisition of polymorphic microsatellites was $18.8 \%$ for di-, $21.9 \%$ for tri-, $18.8 \%$ for tetra-, and $25.0 \%$ for pentanucleotide repeats (Supp. Table 3).
Table 2 Primers sequence (5'$\left.3^{\prime}\right)$ and multiplex composition of PCR 1 and PCR 2 used for rapid identification molecular tool

\begin{tabular}{ll}
\hline PCR 1 & PCR 2 \\
\hline GAZ_F2: CCAACCAYAAAGATATWGGTAC & GAZ_R2: GGATGACCAAARAACCAAAA \\
Ld_R: CTGAATACCACTAAGGGGG & Ld_F2: GACGGTCTACCCCCCCC \\
Lh_R: AGCGATAACAGTAACAAGAAAG & Lh_F2: GGTCTGTCTTAATCACAGCTTTC \\
Hn_R: CATTGTATAACTGGTGATTACCTCC & PC_F: GTCCTGGAAATCAATTTTTAGGAGG \\
\hline
\end{tabular}


Fig. 1 Annealing sites and expected fragment sizes for the five Laminaria species using the rapid identification method. PCR products were pooled from PCR 1 and PCR 2 and include the positive internal control amplification product (601 bp), two fragments for $L$. digitata (345 bp and $386 \mathrm{bp}$ ) and L. hyperborea (574 bp and $166 \mathrm{bp}$ ), one fragment for $H$. nigripes (144 bp), and none for L. ochroleuca

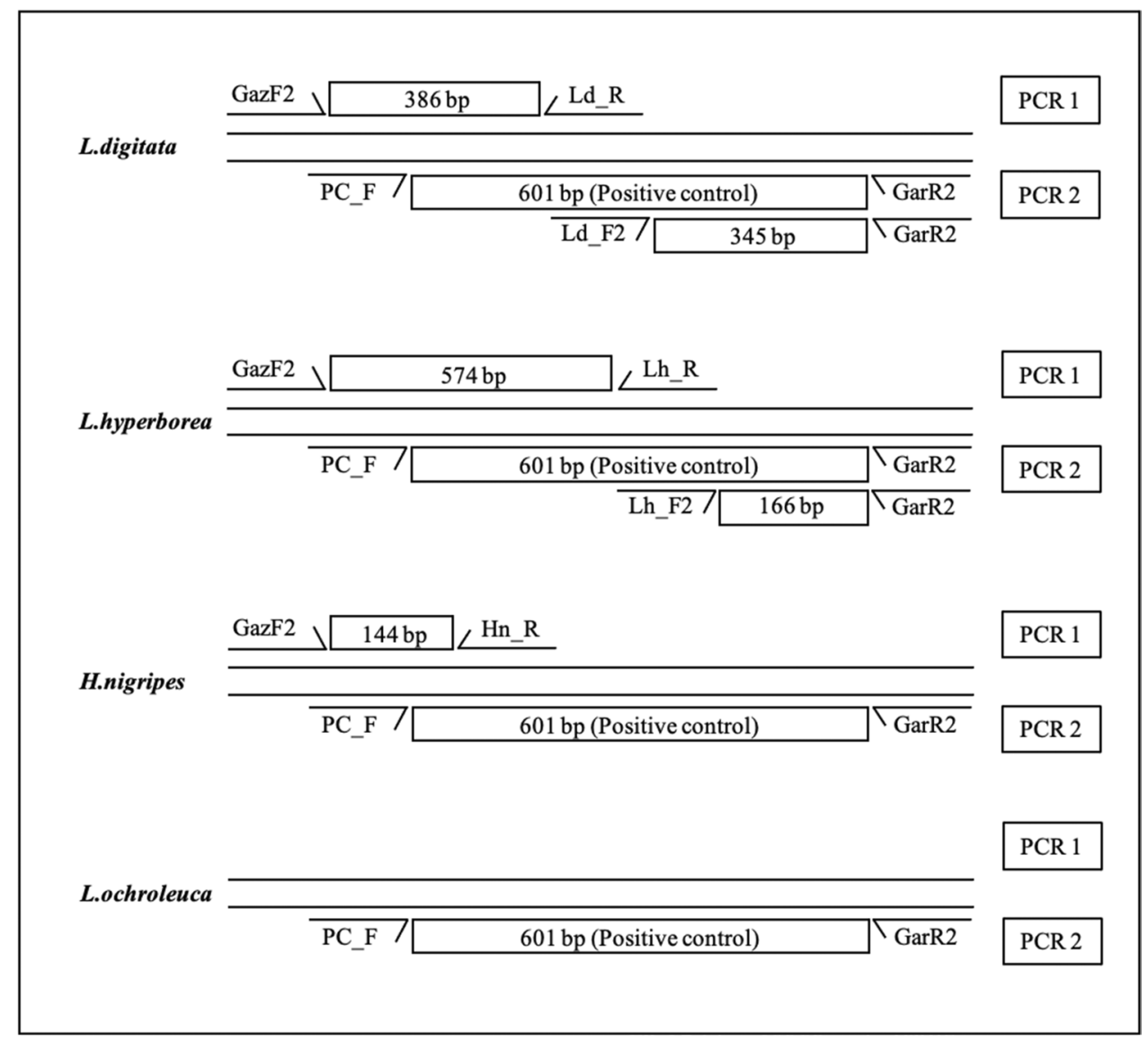

\section{Transferability assessment}

All the loci analyzed in this study (20 microsatellites markers developed in this study, in addition to the 20 previously published ones, see "Materials and methods" section) were selected for their amplification success and their polymorphism (in the case of the new microsatellites markers) in the focal species ( $L$. digitata). Twenty-nine of these 40 markers were successfully amplified in $L$. hyperborea, 28 in L. ochroleuca, 29 in L. rodriguezii, and 22 in L. pallida and 18 markers amplified across all species (Table 1). The proportion of microsatellite markers that cross-amplified decreased with increasing phylogenetic distance from L digitata (Table 3, ranked according to Rothman et al. 2017 phylogeny when considering the 30 markers developed from $L$. digitata genome). In addition, we tested the ascertainment bias hypothesis which stipulates that the median allele length of microsatellites is longer in the species from which the markers were derived (Ellegren et al. 1995). For this purpose, we computed the proportion of markers associated with a higher allelic size in the focal species compared to each sister species taken individually and when taken altogether (Table 4). The percentage of markers which showed a higher allelic size in L. digitata never exceeded $50 \%$, as expected under the ascertainment bias hypothesis, and ranged from 15 to $30 \%$ (corresponding to $L$. rodriguezii and $L$. ochroleuca, respectively, Table 4 ) and dropped to $0 \%$ when considering all sister species (Table 4). Therefore, our results do not seem to support this hypothesis.

\section{Genetic diversity across species}

Null allele frequency, genetic diversity indices, and estimates of departure from random mating $\left(F_{I S}\right)$ are given in Table 5 for each of the 40 loci and species. However, among the loci that correctly amplified, several markers (10 in $L$. digitata, 8 in L. hyperborea, 12 in L. ochroleuca, 11 in $L$. rodriguezii, and 10 in L. pallida, Table 5) were discarded because they appeared to be either monomorphic within populations, amplified in less than $80 \%$ of the individuals, showed a significant frequency of null alleles, or showed an extreme departure from random mating in $L$. digitata suggesting non-Mendelian inheritance $\left(F_{I S}=-0.83\right.$, Table 5). Overall, from our study, 30 markers appear to be useful for L. digitata, 21 for L. hyperborea, 16 for L. ochroleuca, 18 for $L$. rodriguezii, and 12 for $L$. pallida (corresponds to the markers highlighted in light gray in Table 5). Therefore, the number of polymorphic loci at least doubled in the three first 


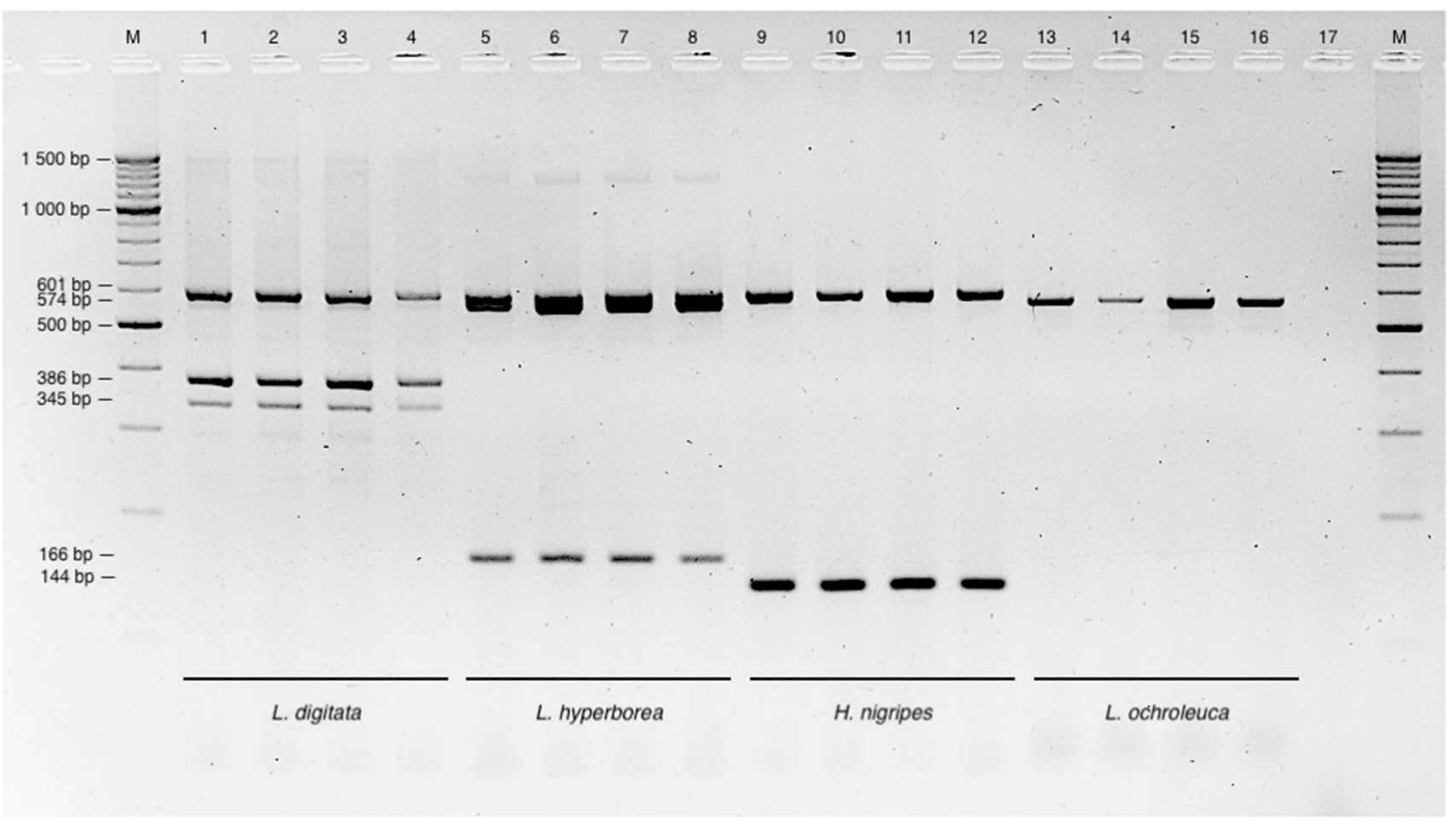

Fig. 2 Gel electrophoresis of PCR amplicons was pooled from PCR 1 and PCR 2 using the rapid species identification tool. (1-4) L. digitata samples; (5-8) L. hyperborea samples; (9-12) H. nigripes sam-

species (17 more polymorphic loci for $L$. digitata, 11 for $L$. hyperborea, 9 for $L$. ochroleuca) compared to the previous studies. In addition, a minimum of 12 new polymorphic loci was developed for L. rodriguezii and L. pallida, for which no microsatellite markers were available before this study.

For L. digitata, the within-population genetic diversity indices of newly developed markers (Table 5) were on average similar to those previously developed from the L. digitata genome (markers from Billot et al. 1998 and Brennan et al. 2014) and were one and a half to two times higher than the ones developed from L. ochroleuca genome (markers from Coelho et al. 2014). It should be noted that seven out of the 10 markers developed from $L$ ochroleuca could not be used in our L. digitata population, either because of the significant frequency of null alleles, the highly significant deviation from random mating (locus LOIVVIV_10, LOIVVIV_16, LOIVVIV_24, LOIVVIV_28), or because they were monomorphic in the studied population (Lo4_24, LOIVVIV_13, LOIVVIV_27).

Table 3 Percentage of primers defined based on the L. digitata genome that amplified in each of the sister Laminaria species

\begin{tabular}{lll}
\hline Compared species & Ratio & $\%$ \\
\hline Lh/Ld & $20 / 30$ & $67 \%$ \\
Lo/Ld & $18 / 30$ & $60 \%$ \\
Lr/Ld & $20 / 30$ & $67 \%$ \\
Lp/Ld & $14 / 30$ & $47 \%$ \\
\hline
\end{tabular}

ples; and (13-16) L. ochroleuca samples. (17) pooled negative control and (M) $100 \mathrm{bp}$ ladder

The level of polymorphism was highly variable among the 30 retained loci for $\mathrm{L}$. digitata, with the number of alleles $(\mathrm{Na})$ ranging from 2 to 16 with a mean value of 5.89 , the expected heterozygosity $(\mathrm{He})$ from 0.092 to 0.910 with a mean value of 0.581 and PIC from 0.089 to 0.868 with a mean value of 0.537 , while the departure from random mating $\left(F_{I S}\right)$ was less variable among loci ranging from -0.264 to 0.305 with a mean value of 0.048 .

For all sister species, we observed a slight decrease in genetic diversity with increasing genetic distance from $L$. digitata (whichever the diversity index and the set of markers, Table 5). However, a non-negligible number of markers remained informative as illustrated by the PIC values

Table 4 Percentage of microsatellite markers with a higher allelic size in the focal species compared to the sister species

\begin{tabular}{lll}
\hline Compared species & Ratio & $\%$ \\
\hline$L h / L d$ & $4 / 19$ & $21 \%$ \\
$L o / L d$ & $5 / 18$ & $30 \%$ \\
$L r / L d$ & $3 / 20$ & $15 \%$ \\
$L p / L d$ & $4 / 14$ & $28 \%$ \\
$(L h+L o+L r+L p) / L d *$ & $0 / 10$ & $0 \%$ \\
\hline
\end{tabular}

Ld L. digitata, Lh L. hyperborea, Lo L. ochroleuca, Lr L. rodriguezii, Lp L. pallida

*In this comparison, we took into account only the markers that amplified in all sister species 


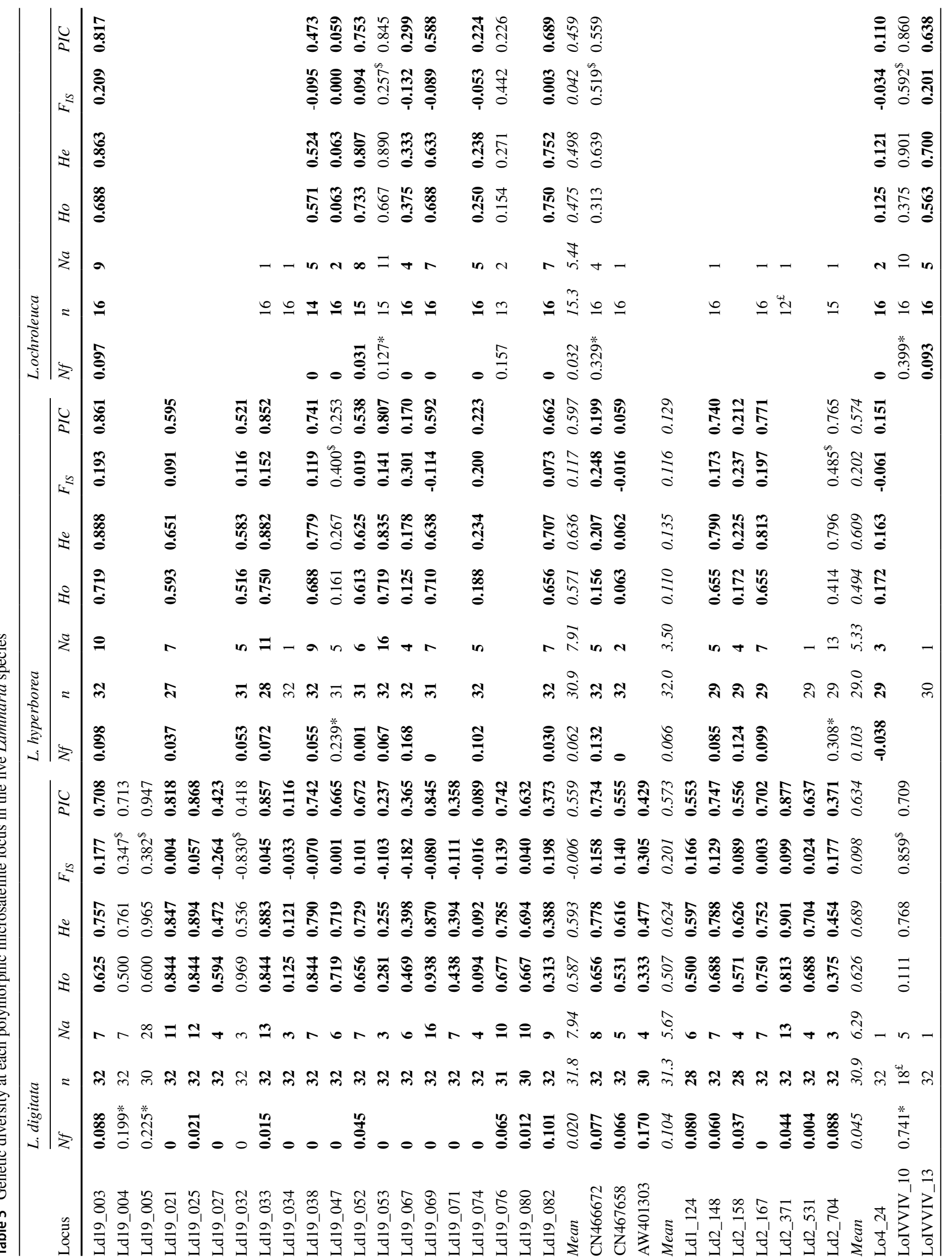




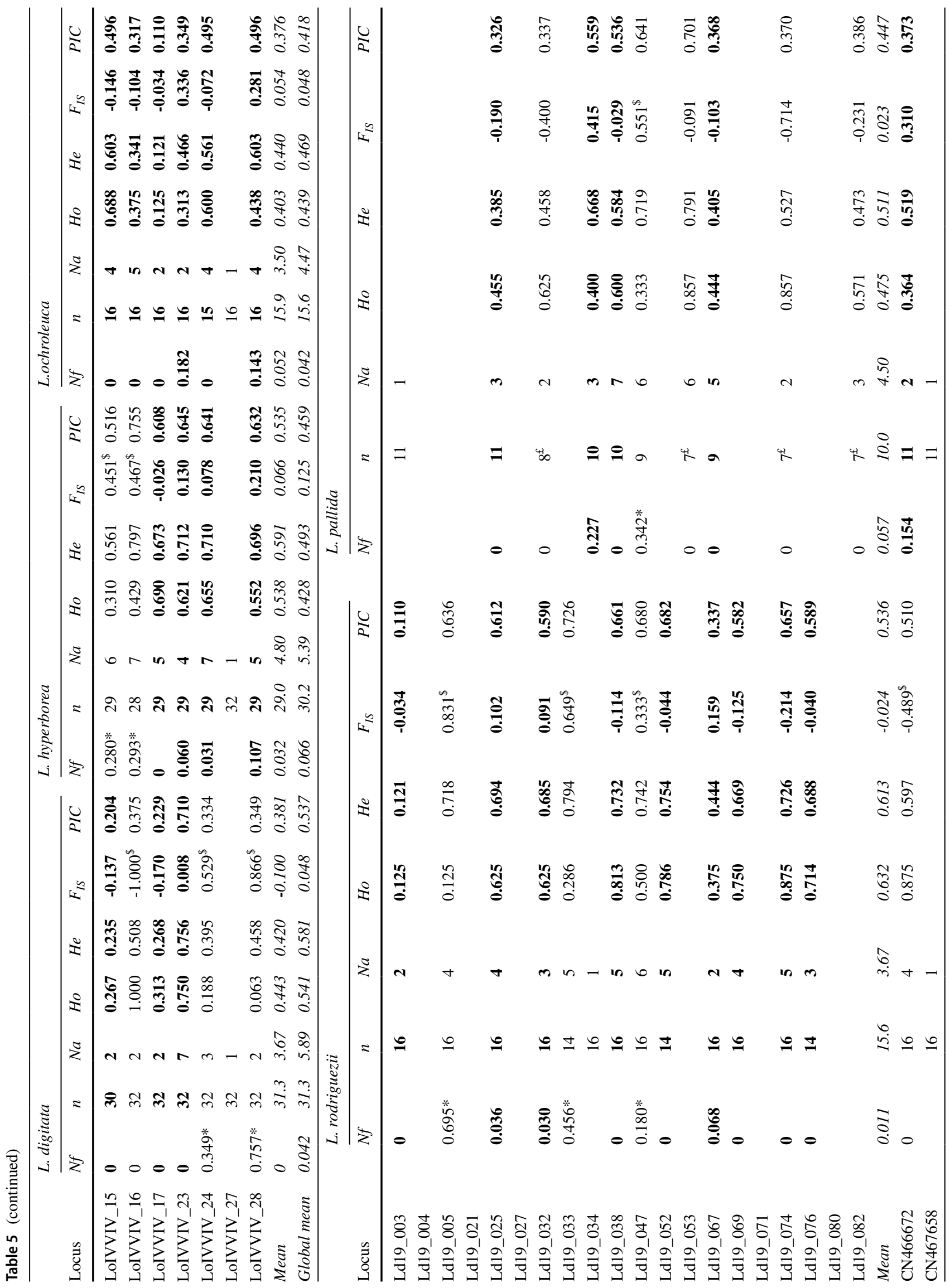




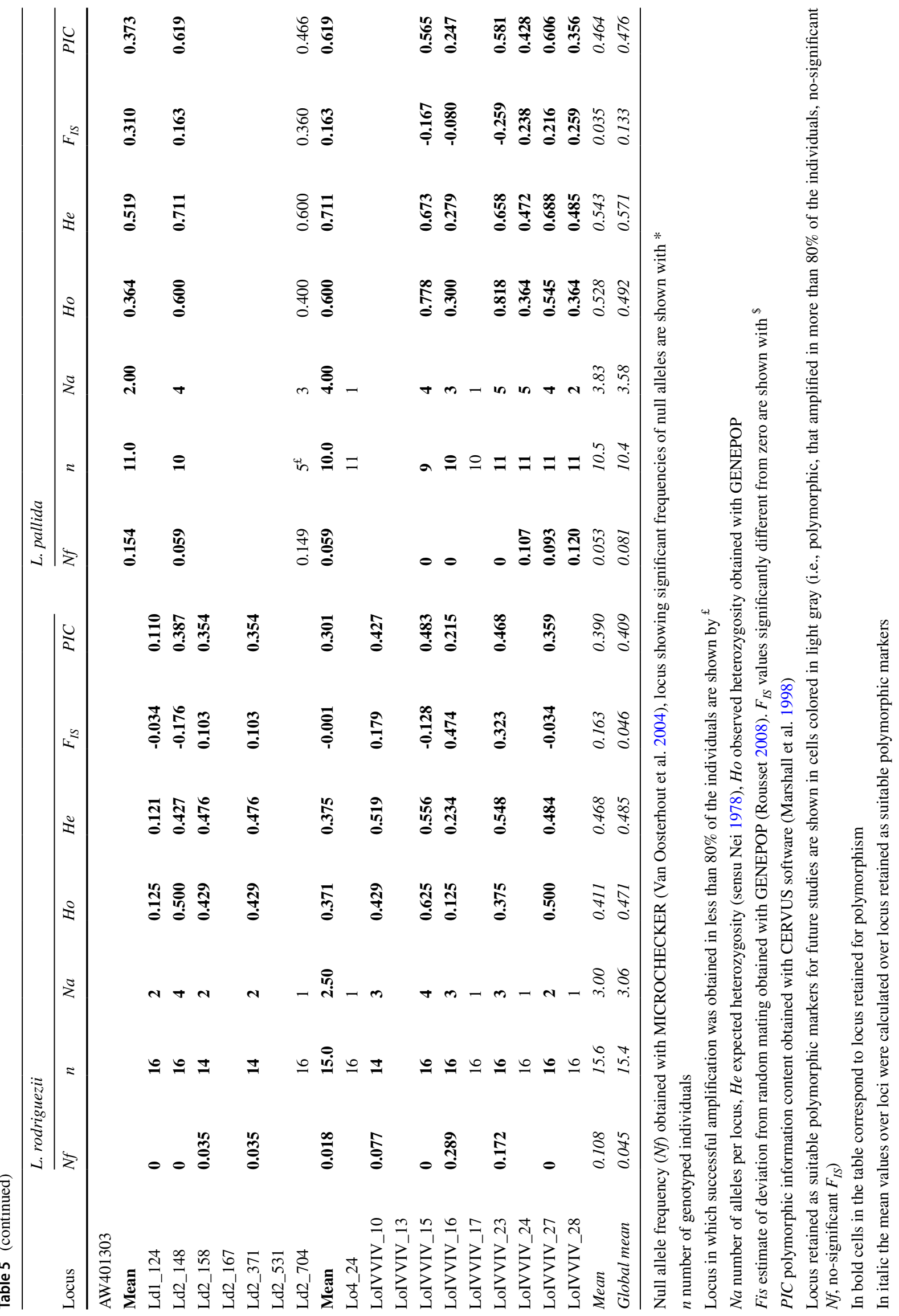


being higher than 0.5 , as well as the expected and observed heterozygosity.

\section{Rapid species identification}

Amplification of COI using the two sets of species-specific multiplex PCR primers provided direct identification of the four species of North-Atlantic kelps (L. digitata, L. hyperborea, L. ochroleuca, and H. nigripes) with $100 \%$ accuracy (Fig. 2). All the combination of primers (GAZ_F2/Ld_R/ Lh_R/Hn_R and GAZ_R2/Ld_F2/Lh_F2/PC_F) showed positive internal control amplification products (601 bp). Multiplex PCR amplification produced the expected sizes and number of fragments for each species: two fragments for L. digitata (345 bp and $386 \mathrm{bp}$ ) and for L. hyperborea (574 bp and $166 \mathrm{bp}$ ), one fragment for H. nigripes (144 bp), and none for L. ochroleuca (Fig. 2 and Supp. Table 5).

\section{Discussion}

In this study, we developed highly informative microsatellite markers for five closely related species of the genus Laminaria, in addition to a molecular tool for rapid identification of morphologically similar species. We will first discuss the technical aspects and possible phylogenetic bias of microsatellite development and then focus on the potential use of the new markers.

\section{Characteristics of microsatellites and transferability between species}

With the increasing number of sequenced genomes, in silico mining of simple sequence repeats (SSR) from genome sequence databases has been widely used for microsatellite detection in plants and animals (see references in Wang et al. 2019). This method is less time-consuming and more effective than earlier methods based on the construction and screening of microsatellite enriched library (Zane et al. 2002). The occurrence and the frequency of different types of motifs among microsatellites seem to be characteristic to species, which could be among distantly or closely related species (see for review in Wang et al. 2019; Zhu et al. 2021). In the present study, trinucleotide repeats were found to be the most abundant motif (49.6\%), but the low number of sequenced genomes in brown seaweed is still not sufficient to characterize the distribution and motif across species (Zhu et al. 2021), or even to explore their putative biological functions. The most common class of polymorphic marker contained trinucleotide motifs for each sister species (33-50\% of the polymorphic markers), except for $L$. pallida for which polymorphic markers with tetranucleotide motifs were the most abundant (44\% of the polymorphic markers). Dinucleotide and pentanucleotide repeats were the least abundant type of polymorphic marker for all sister species $(0-17 \%$ for dinucleotide and $0-22 \%$ for pentanucleotide). However, microsatellite loci constituted by three to five repeated motifs are easier to score than markers with dinucleotide repeats, because the latter show "stutter" bands (multiple PCR products from the same fragment that are typically shorter by one or a few repeats than the full-length product, Chambers and MacAvoy 2000), possibly leading to technical bias.

The ability to effectively transfer microsatellite markers across taxa has been successfully demonstrated in many species (see for review in plants: Ellis and Burke 2007; in animals: Hutter et al. 1998; and in kelps: Liu et al. 2012; Coelho et al. 2014; Zhang et al. 2015). The results of many studies have clearly indicated that EST-derived microsatellite markers have a higher transfer rate compared to those developed from anonymous nuclear DNA regions, due to greater DNA sequence conservation in transcribed versus non-coding regions. Cross-amplification success rate is correlated with phylogenetic distance and is, predictably, highest among closely related congeners, but it has been exceptionally reported across multiple genera within a family (see for review Kalia et al. 2011). In our study, we mostly tested cross-amplification for anonymous nuclear-derived microsatellites (27 loci) since only three EST-derived markers were available. The level of transferability within Laminaria was quite high, ranging from 47 to $67 \%$ and, as expected, decreased proportionally to the genetic distance between L. digitata and the other Laminaria species. Consequently, the use of microsatellites developed by cross-amplification from other taxa can possibly lead to various types of bias. Moreover, several studies using cross-species amplification techniques have demonstrated that microsatellite alleles are longer and more variable in the species from which they were derived (see references in Hutter et al. 1998). This observation could result from an ascertainment bias in the selection of clones when sequencing because the screening conditions in the focus species favor the identification of clones with long repeat units (Ellegren et al. 1995) and the presence of polymorphism. This bias in allele size was not confirmed in this study, but we did find a slight decrease in genetic diversity with an increase in the genetic distance with $L$. digitata.

\section{Potential uses of the new developed microsatellites and species identification markers}

Microsatellites are among the most frequently used markers to study intraspecific genetic diversity in population genetics, conservation genetics, and evolutionary studies. They also represent a molecular tool of great interest for applied seaweed research (see for review Brakel et al. 2021), such 
as when identifying genetic resources in wild populations, or assessing the level of connectivity between populations for seaweed aquaculture.

In this study, for the first time, we defined 12 polymorphic loci for the South African L. pallida and 18 for the rare Mediterranean-endemic $L$. rodriguezii. This could be particularly interesting for L. pallida, which has not been investigated so far despite its ecological importance and biogeographical significance. For $L$. rodriguezii, genetic diversity within populations was until now only investigated using more than 4000 SNPs (Reynes et al. 2021). These technological advances in next-generation sequencing (NGS) are becoming available for studying population genetics in non-model organisms including kelps, such as reduced-representation sequencing (RRS) (Rad-seq SNPs: Guzinski et al. 2018, 2020; Reynes et al., 2021; Vranken et al. 2021) and whole genome sequencing (WGS, Graf et al. 2021). In contrast with microsatellite loci that inform about patterns of genetic variation that result from neutral or stochastic processes; these new population genomic approaches characterized by a better covering of the genome allow to search for loci associated with coding regions and can be used to quantify adaptive variation and inform about functional deterministic processes such as selection. In addition, RRS and WGS were shown to increase power and allow, in principle, for clearer detection and higher resolution of neutral genetic structure by increasing the number of markers compared to microsatellites. In particular cases, a limited number of highly polymorphic microsatellites (10) can perform as well as thousands of SNPs $(10,615)$ to investigative neutral genetic structure of the kelp species Undaria pinnatifida (Guzinski et al. 2018), though with some advantages including rapid genotyping without the need to introduce strong bioinformatic background.

In $L$. rodriguezii, Reynes et al. (2021) demonstrated that SNPs markers were indeed highly efficient to investigate partial clonality under a population genomic approach and identified a particularly high level of genetic differentiation in comparison to other kelps. Nevertheless, the use of SNPs from RRS is far more expensive compared to microsatellite genotyping, and their study was restricted to a rather small number of individuals $(N=43)$. Therefore, the 18 newly developed microsatellite loci in this species can still be seen as a good alternative to extend genetic structure analysis to a larger sampling size but also to perform comparative analyses between the five kelp species, as the same loci can be used across species.

In the three North Atlantic kelps, seven to 15 microsatellites were already available and mainly used to reconstruct their phylogeography and to analyze the level of connectivity in relation to life history traits and environmental factors (Billot et al. 2003; Valero et al. 2011; Couceiro et al. 2013; Robuchon et al. 2014; Assis et al. 2018; Evankow et al. 2019; King et al. 2019; Liesner et al. 2020; Neiva et al. 2020; Schoenrock et al. 2020). The number of polymorphic loci at least doubled in these species (17 new polymorphic loci out of 30 for L. digitata, 11 out of 21 for L. hyperborea, and 9 out of 16 for L. ochroleuca), significantly improving the power of detection of genetic diversity and differentiation. These new markers should lead to a better estimation of the pattern of intraspecific genetic diversity and may also open up the possibility of carrying out studies that require higher individual discrimination power, such as parentage assignment studies. Consequently, the new markers will not only help to further elucidate the origins and demographic history of the NW Atlantic populations (e.g., Neiva et al. 2020) but also the species' adaptation potential, which is an increasingly important factor for sustainable conservation, exploitation of wild resources and to implement cultivation. In this context, the newly developed markers can be seen as a step towards expanding the repertoire of genetic toolsets, while we wait for higher resolution options to become more accessible.

Finally, we have presented species-specific primers based on the mitochondrial COI gene in order to discriminate $L$. digitata, L. hyperborea, L. ochroleuca, and H. nigripes based on the rapid species identification method developed in Brachionus (Seudre et al. 2020) and Agarophyton (Huanel et al. 2020). The multiplex PCR amplification of the specific primers produced fragments of different sizes for each species, and the specific primers were tested in a small panel of other co-occurring and potentially confounding kelp species (Saccharina latissima (Linnaeus) C.E. Lane, C. Mayes, Druehl \& G.W. Saunders, Saccorhiza polyschides (Lightfoot) Batters), confirming the sensitivity of the approach, and they never produced band patterns similar to L. digitata, L. hyperborea, and $H$. nigripes. This method does not require Sanger sequencing and therefore is much faster and cheaper. This method should avoid taxonomic confusions and could be particularly helpful when sampling in areas where species range distributions overlap, particularly along the Arctic and the NW Atlantic where L. digitata and $H$. nigripes often occur in mixed stands. This rapid method of correctly assigning individuals to species is essential for the design of appropriate management and conservation of these kelp species. As many cryptic species are constantly discovered in algae (Leliaert and Clerck 2017), the ability of conservation and management programs to correctly distinguish species is an issue that can be easily addressed with the rapid identification method proposed here. In the field of speciation and biogeography, the correct identification of sympatric morphologically similar species may change our understanding of the history of algal lineage diversification and also allow the identification of recent introductions. Another useful application includes pre-screening of samples for non-genetic studies, such as physiological 
experiments dealing with species-specific responses to thermal stress, where fast and cheap identification of dozens of samples may be a necessity. The identification of juvenile stages can also be problematic but critical in the context of ecologic and monitoring studies. Another challenging question in the ecology of kelp is to better understand the role of the microscopic gametophytes in the field. Recently, Bringloe et al. (2018) have successfully used a PCR identification method based on species-specific nuclear ITS of the ribosomal cistron primers of Alaria esculenta and L. digitata to detect the presence of gametophotypes of these two kelps species on different red algae hosts. We did not test if the rapid identification method developed in our paper could also be used to detect the occurrence of gametophytes, but we suppose that this method should be very efficient when gametophyte detection is done on phylogenetically distant host species as in Bringloe et al. (2018). On the other hand, in order to detect the presence of gametophytes on a sporophyte of these four kelp species, it would be necessary to modify the method in order not to mix the primers of the four species. Indeed, our method shows that we never identify more than a single species even if the target sporophytes were sampled in sites where the different species co-occurred in sympatry (see for example the two Norway sites: Stubhallet and Hansneset, in which 52 individuals where sampled, 18 and 34, respectively, in each site, resulting in the identification of $38 \mathrm{~L}$. digitata and $14 \mathrm{H}$. nigripes sporophytes, Supp. Table 1). Even though the gametophytes of the two sympatric species were potentially present on sporophytes, only the primers of the target sporophyte were amplified, probably because the amount of DNA present in the gametophytes was negligible compared to those of the sporophyte.

Supplementary Information The online version contains supplementary material available at https://doi.org/10.1007/s10811-021-02613-x.

Acknowledgements We would like to thank Mark Cock and the two anonymous reviewers for their comments on the manuscript. We are grateful to the Roscoff Bioinformatic platform (ABiMS) for bioinformatics support and to the Biogenouest genomics core facility (Genomer Plateforme génomique at the Biological Station of Roscoff) for their technical support. The authors are deeply indebted to the Service Mer \& Observation (SMO) of Roscoff, I. Bartsch, C. Billot, G. Cervin, M. Coleman, C. Destombe, L. Dupont, C. Engel, L. Erting, S. Fredriksen, C. Gehring, F. Gevaert, K. Gunnarsson, C. Maggs, F. Mineur, M. Oriot, G. Pearson, T. Pereira, A. Peters, G. Saunders, and A. Tayalé for sampling.

Author contribution S. Mauger: laboratory work, bioinformatics analysis, analysis of molecular data, led manuscript drafting and editing; L. Fouqueau: analysis of molecular data, led manuscript drafting and editing; K. Avia: bioinformatics analysis, editing manuscript; L. Reynes: sampling and editing manuscript; EA. Serrao: sampling and editing manuscript; J. Neiva: editing manuscript; M. Valero: original concept, funding and supervision, sampling, drafting and editing manuscript.
Funding This work benefited from the support of the French Government through the National Research Agency with regard to an investment expenditure program IDEALG (ANR-10-BTBR-04), the EU Horizon 2020 project GENIALG (Grant Agreement No 727892), and the France Génomique project Phaeoexplorer (ANR-10-INBS-09). LF is funded by the European Community (project MARFOR Biodiversa/004/2015) and the Region Bretagne (ARED 2017 REEALG). CCMAR was funded by FCT-Foundation for Science and Technology (Portugal) UIDB/04326/2020, DL57/2016/CP1361/CT0010 SFRH/BSAB/150485/2019, a Pew Marine Fellowship, and the Benguela Current Convention (BCC) project BCLME III funded by Global Environment Facility (GEF) and United Nations Development Program (UNDP) for the Namibian sampling.

Data availability All data generated during this study are openly available in a Dryad Digital Repository (https://doi.org/10.5061/dryad. 612jm643j).

\section{Declarations}

Conflict of interest The authors declare no competing interests.

\section{References}

Allendorf FW, Ryman N (2002) The role of genetics in population viability analysis. In: Beissinger SR, McCullough DR (eds) Population viability analysis. University of Chicago Press, Chicago, pp 50-85

Araújo RM, Assis J, Aguillar R, Airoldi L, Bárbara I, Bartsch I, Bekkby T, Christie H, Davoult D, Derrien-Courtel S, Fernandez C, Fredriksen S, Gevaert F, Gundersen H, Le Gal A, Lévêque L, Mieszkowska N, Norderhaug KM, Oliveira P, Puente A, Rico JM, Rinde E, Schubert H, Strain EM, Valero M, Viard F, Sousa-Pinto I (2016) Status, trends and drivers of kelp forests in Europe: an expert assessment. Biodivers Conserv 25:1319-1348

Assis J, Serrão EÁ, Coelho NC, Tempera F, Valero M, Alberto F (2018) Past climate changes and strong oceanographic barriers structured low-latitude genetic relics for the golden kelp Laminaria ochroleuca. J Biogeogr 45:2326-2336

Ballesteros E (2006) Mediterranean coralligenous assemblages: a synthesis of present knowledge. Oceanogr Mar Biol 44:123-195

Bartsch I, Wiencke C, Bischof K, Buchholz CM, Buck BH, Eggert A, Feuerpfeil P, Hanelt D, Jacobsen S, Karez R, Karsten U, Molis M, Roleda MY, Schubert H, Schumann R, Valentin K, Weinberger F, Wiese J (2008) The genus Laminaria sensu lato: recent insights and developments. Eur J Phycol 43:1-86

Billot C, Engel CR, Rousvoal S, Kloareg B, Valero M (2003) Current patterns, habitat discontinuities and population genetic structure: the case of the kelp Laminaria digitata in the English channel. Mar Ecol Prog Ser 253:111-121

Billot C, Rousvoal S, Estoup A, Epplen T, Saumitou-Laprade P, Valero M, Kloareg B (1998) Isolation and characterization of microsatellite markers in the nuclear genome of the brown alga Laminaria digitata (Phaeophyceae). Mol Ecol 7:1778-1780

Bolton JJ (2010) The biogeography of kelps (Laminariales, Phaeophyceae): a global analysis with new insights from recent advances in molecular phylogenetics. Helgol Mar Res 64:263-279

Brakel J, Sibonga RC, Dumilag RV, Montalescot V, Campbell I, Cottier-Cook J, Ward G, Le Masson V, Liu T, Msuya FE (2021) Exploring, harnessing and conserving marine genetic resources towards a sustainable seaweed aquaculture. Plants People Planet 3:337-349 
Bringloe TT, Bartlett CAB, Bergeron ES, Cripps KSA, Daigle NJ, Gallagher PO, Gallant AD, Giberson ROJ, Greenough SJ, Lamb JM, Leonard TW, MacKay JA, McKenzie AD, Persaud SM, Sheng T, Mills AMES, Moore TE, Saunders GW (2018) Detecting Alaria esculenta and Laminaria digitata (Laminariales, Phaeophyceae) gametophytes in red algae, with consideration of distribution patterns in the intertidal zone. Phycologia 57:1-8

Brennan G, Kregting L, Beatty GE, Cole C, Elsäßer B, Savidge G, Provan J (2014) Understanding macroalgal dispersal in a complex hydrodynamic environment: a combined population genetic and physical modelling approach. J R Soc Interface 11:1-12

Chambers GK, MacAvoy ES (2000) Microsatellites: consensus and controversy. Comp Biochem Physiol B 126:455-476

Coelho NC, Serrão EA, Alberto F (2014) Characterization of fifteen microsatellite markers for the kelp Laminaria ochroleuca and cross species amplification within the genus. Conserv Genet Resource 6:949-950

Couceiro L, Robuchon M, Destombe C, Valero M (2013) Management and conservation of the kelp species Laminaria digitata: using genetic tools to explore the potential exporting role of the MPA "Parc naturel marin d'Iroise." Aquat Living Resour 26:197-205

Ellegren H, Primmer CR, Sheldon B (1995) Microsatellite evolution: directionality or bias in locus selection? Nat Genet 11:60-62

Ellis JR, Burke JM (2007) EST-SSRs as a resource for population genetic analyses. Heredity (Edinb) 99:125-132

Evankow A, Christie H, Hancke K, Brysting AK, Junge C, Fredriksen S, Thaulow J (2019) Genetic heterogeneity of two bioeconomically important kelp species along the Norwegian coast. Conserv Genet 20:615-628

Fredriksen S, Karsten U, Bartsch I, Woelfel J, Koblowsky M, Schumann R, Moy SR, Steneck RS, Wiktor JM, Hop H, Wiencke C (2019) Biodiversity of benthic macro- and microalgae from Svalbard with special focus on Kongsfjorden. In: Hop H, Wiencke C (eds) The ecosystem of Kongsfjorden, Svalbard, vol 2. Springer, Cham, pp 331-371

Guzinski J, Mauger S, Cock JM, Valero M (2016) Characterization of newly developed expressed sequence tag-derived microsatellite markers revealed low genetic diversity within and low connectivity between European Saccharina latissima populations. J Appl Phycol 28:3057-3070

Guzinski J, Ballenghien M, Daguin-Thiébaut C, Lévêque L, Viard F (2018) Population genomics of the introduced and cultivated Pacific kelp Undaria pinnatifida: marinas-not farms-drive regional connectivity and establishment in natural rocky reefs. Evol Appl 11:1582-1597

Guzinski J, Ruggeri P, Ballenghien M, Mauger S, Jacquemin B, Jollivet C, Coudret J, Jaugeon L, Destombe C, Valero M (2020) Seascape genomics of the sugar kelp Saccharina latissima along the North Eastern Atlantic latitudinal gradient. Genes 11:1503

Graf L, Shin Y, Yang JH, Choi JW, Hwang IK, Nelson W, Bhattacharya D, Viard F, Yoon HS (2021) A genome-wide investigation of the effect of farming and human-mediated introduction on the ubiquitous seaweed Undaria pinnatifida. Nature Ecol Evol 5:360-368

Huanel OR, Nelson WA, Robitzch V, Mauger S, Faugeron S, Preuss M, Zuccarello GC, Guillemin ML (2020) Comparative phylogeography of two Agarophyton species in the New Zealand archipelago. J Phycol 56:1575-1590

Hutter CM, Schug MD, Aquadro CF (1998) Microsatellite variation in Drosophila melanogaster and Drosophila simulans: A reciprocal test of the ascertainment bias hypothesis. Mol Biol Evol 15:1620-1636

Jayathilake DR, Costello MJ (2021) Version 2 of the world map of laminarian kelp benefits from more Arctic data and makes it the largest marine biome. Biol Conservat 257:109099
Kalia RK, Rai MK, Kalia S, Singh R, Dhawan AK (2011) Microsatellite markers: an overview of the recent progress in plants. Euphytica 177:309-334

King NG, McKeown NJ, Smale DA, Wilcockson DC, Hoelters L, Groves EA, Stamp T, Moore PJ (2019) Evidence for different thermal ecotypes in range centre and trailing edge kelp populations. J Exp Mar Biol Ecol 514-515:10-17

Krumhansl KA, Okamoto DK, Rassweiler A, Novak M, Bolton JJ, Cavanaugh KC, Connell SD, Johnson CR, Konar B, Ling SD, Micheli F, Norderhaug KM, Pérez-Matus A, Sousa-Pinto I, Reed DC, Salomon AK, Shears NT, Wernberg T, Anderson RJ, Barrett NS, Buschmann AH, Carr MH, Caselle JE, Derrien-Courtel S, Edgar GJ, Edwards M, Estes JA, Goodwin C, Kenner MC, Kushner DJ, Moy FE, Nunn J, Steneck RS, Vásquez J, Watson J, Witman JD, Byrnes JEK (2016) Global patterns of kelp forest change over the past half-century. Proc Natl Acad Sci U S A 113:13785-13790

Lane CE, Lindstrom SC, Saunders GW (2007) A molecular assessment of northeast Pacific Alaria species (Laminariales, Phaeophyceae) with reference to the utility of DNA barcoding. Mol Phylogenet Evol 44:634-648

Leliaert F, De Clerck O (2017) Refining species boundaries in algae. J Phycol 53:12-16

Liesner D, Fouqueau L, Valero M, Roleda MY, Pearson GA, Bischof K, Valentin K, Bartsch I (2020) Heat stress responses and population genetics of the kelp Laminaria digitata (Phaeophyceae) across latitudes reveal differentiation among North Atlantic populations. Ecol Evol 10:9144-9177

Liu F, Wang F, Duan D (2012) EST-SSR markers derived from Laminaria digitata and its transferable application in Saccharina japonica. J Appl Phycol 24:501-505

Longtin CM, Saunders GW (2015) On the utility of mucilage ducts as a taxonomic character in Laminaria and Saccharina (Phaeophyceae) - the conundrum of $S$. groenlandica. Phycologia 54:440-450

Longtin CM, Saunders GW (2016) The relative contribution of Saccharina nigripes (Phaeophyceae) to the Bay of Fundy Laminariaceae: spatial and temporal variability. Mar Ecol Prog Ser 543:153-162

Marins BV, Amado-Filho GM, Barbarino E, Pereira-Filho GH, Longo LL (2014) Seasonal changes in population structure of the tropical deep-water kelp Laminaria abyssalis. Phycol Res 62:55-62

Marshall TC, Slate J, Kruuk LEB, Pemberton JM (1998) Statistical confidence for likelihood-based paternity inference in natural populations. Mol Ecol 7:639-655

Mauger S, Couceiro L, Valero M (2012) A simple and cost-effective method to synthesize an internal size standard amenable to use with a 5-dye system. Prime Res Biotechnol 2:40-46

McDevit DC, Saunders GW (2009) On the utility of DNA barcoding for species differentiation among brown macroalgae (Phaeophyceae) including a novel extraction protocol. Phycol Res 57:131-141

Nei M (1978) Estimation of average heterozygosity and genetic distance from a small number of individuals. Genetics 89:583-590.

Neiva J, Serrão EA, Paulino C, Gouveia L, Want A, Tamigneaux E, Ballenghien M, Mauger S, Fouqueau L, Engel-Gautier C, Destombe C, Valero M (2020) Genetic structure of amphi-Atlantic Laminaria digitata (Laminariales, Phaeophyceae) reveals a unique range-edge gene pool and suggests post-glacial colonization of the NW Atlantic. Eur J Phycol 55:517-528

Reynes L, Thibaut T, Mauger S, Blanfuné A, Holon F, Cruaud C, Couloux A, Valero M, Aurelle D (2021) Genomic signatures of clonality in the deep water kelp Laminaria rodriguezii. Mol Ecol 30:1806-1822

Robuchon M, Le Gall L, Mauger S, Valero M (2014) Contrasting genetic diversity patterns in two sister kelp species co-distributed along the coast of Brittany, France. Mol Ecol 23:2669-2685

Rothman MD, Mattio L, Anderson RJ, Bolton JJ (2017) A phylogeographic investigation of the kelp genus Laminaria (Laminariales, 
Phaeophyceae), with emphasis on the South Atlantic Ocean. J Phycol 53:778-789

Rousset F (2008) GENEPOP'007: a complete re-implementation of the genepop software for Windows and Linux. Mol Ecol Resour $8: 103-106$

Rozen S, Skaletsky H (2000) Primer3 on the WWW for general users and for biologist programmers. Meth Mol Biol 2000:365-386

Saunders GW (2005) Applying DNA barcoding to red macroalgae: a preliminary appraisal holds promise for future applications. Philos Trans R Soc B 360:1879-1888

Schoenrock KM, O’ Connor AM, Mauger S, Valero M, Neiva J, Serrão EA, Krueger-Hadfield SA (2020) Genetic diversity of a marine foundation species, Laminaria hyperborea (Gunnerus) Foslie, along the coast of Ireland. Eur J Phycol 55:310-326

Seudre O, Vanhoenacker E, Mauger S, Coudret J, Roze D (2020) Genetic variability and transgenerational regulation of investment in sex in the monogonont rotifer Brachionus plicatilis. J Evol Biol 33:112-120.

Smale DA (2020) Impacts of ocean warming on kelp forest ecosystems. New Phytol 225:1447-1454

Soulé ME, Mills LS (1992) Conservation genetics and conservation biology: a troubled marriage. In: Sandlund OT, Hindar K, Brown AHD (eds) Conservation of biodiversity for sustainable development. Scandinavian University Press, Oslo, pp 55-69

Starko S, Soto Gomez M, Darby H, Demes KW, Kawai H, Yotsukura N, Lindstrom SC, Keeling PJ, Graham SW, Martone PT (2019) Corrigendum to "A comprehensive kelp phylogeny sheds light on the evolution of an ecosystem". Mol Phylogenet Evol 136:138-150.

Steneck RS, Graham MH, Bourque BJ, Corbett D, Erlandson JM, Estes JA, Tegner MJ (2002) Kelp forest ecosystems: biodiversity, stability, resilience and future. Environ Conserv 29:436-459

Teagle H, Hawkins SJ, Moore PJ, Smale DA (2017) The role of kelp species as biogenic habitat formers in coastal marine ecosystems. J Exp Mar Biol Ecol 492:81-98
Valero M, Destombe C, Mauger S, Ribout C, Engel CR, DaguinThiebaut C, Tellier F (2011) Using genetic tools for sustainable management of kelps: a literature review and the example of Laminaria digitata. Cah Biol Mar 52:467-483

Van Oosterhout C, Hutchinson WF, Wills DPM, Shipley P (2004) MICRO-CHECKER: software for identifying and correcting genotyping errors in microsatellite data. Mol Ecol Notes 4:535-538

Vranken S, Wernberg T, Scheben A, Severn-Ellis AA, Batley J, Bayer PE, Edwards D, Wheeler D, Coleman MA (2021) Genotype-environment mismatch of kelp forests under climate change. Molec Ecol 30:3730-3746

Wang X-T, Zhang Y-J, Liang Q, Chen B (2019) Comparative analyses of simple sequence repeats (SSRs) in 23 mosquito species genomes: identification, characterization and distribution (Diptera: Culicidae). Insect Sci 26:607-619

Wernberg T, Coleman MA, Bennett S, Thomsen MS, Tuya F, Kelaher BP (2018) Genetic diversity and kelp forest vulnerability to climatic stress. Sci Rep 8:1-8

Wernberg T, Smale DA, Tuya F, Thomsen MS, Langlois TJ, De Bettignies T, Bennett S, Rousseaux CS (2012) An extreme climatic event alters marine ecosystem structure in a global biodiversity hotspot. Nat Clim Chang 3:78-82

Zane L, Bargelloni L, Patarnello T (2002) Strategies for microsatellite isolation : a review. Mol Ecol 11:1-16

Zhang J, Li W, Qu J, Wang X, Liu C, Liu T (2015) Development and characterization of microsatellite markers from an enriched genomic library of Saccharina japonica. J Appl Phycol 27:479-487

Zhu L, Wu H, Li H, Tang H, Zhang L, Xu H, Jiao F, Wang N, Yang L (2021) Short tandem repeats in plants: genomic distribution and function prediction. Electron J Biotechnol 50:37-44

Publisher's note Springer Nature remains neutral with regard to jurisdictional claims in published maps and institutional affiliations. 